\title{
Controle sobre o trabalho e saúde mental: resgatando conceitos, pesquisas e possíveis relações ${ }^{1}$
}

\author{
Ana Paula Lopes dos Santos ${ }^{\mathrm{I}, 2}$ e Augusto Dutra Galery ${ }^{\mathrm{II}}$ \\ ${ }^{\text {I }}$ Programa de Doutorado em Saúde Coletiva da Universidade Federal de São Paulo \\ ${ }^{\text {II }}$ Programa de Doutorado em Psicologia Social da Universidade de São Paulo
}

\begin{abstract}
No presente artigo buscamos comparar, a partir de uma revisão bibliográfica, as teorias de Louis Le Guillant e Christophe Dejours em relação ao controle sobre o trabalho e seu impacto sobre a saúde mental dos trabalhadores. Para tanto, utilizamos as análises de pesquisas, realizadas por esses dois autores, tendo as telefonistas de Paris como universo. A principal categoria de análise para entender as semelhanças e diferenças entre eles foram suas teorias de base, a saber, o marxismo, no caso de Le Guillant, e a psicanálise, no caso de Dejours. Dessa forma, pudemos concluir que o controle sobre o trabalho tem importantes impactos sobre a saúde mental das telefonistas nas duas opções teóricas. Porém, o papel do contexto organizacional e a centralidade do trabalho como campo de estudo parece diferir, dependendo da teoria de base utilizada.
\end{abstract}

Palavras-chave: Saúde Mental e Trabalho, Controle sobre o trabalho, Controle sobre os trabalhadores, Telefonistas.

Control over work and mental health: reviewing concepts, research and possible relations

This paper reviewed and compared the theories of Louis Le Guillant and Christophe Dejours related to control over work and its impacts on worker's mental health. To do so, we used the researches these two authors had conducted among telephone operators in Paris. The main analysis category we have used to understand similitudes and differences between them was their base theory - marxism, to Le Guillant, and psychoanalysis, to Dejours. We could infer from our study that control over work has important impacts over telephone operators' mental health in both conceptions, but the role of organizational context and the centrality of control as a study field seems to differ, depending on the base theory used.

Keywords: Mental Health and Work, Control over work, Control over workers, Telephone operators.

\section{O campo de Saúde Mental e Trabalho: um olhar sobre as dimensões do controle no trabalho}

$\mathrm{O}$ crescente número de publicações e estudos acadêmicos relacionados à Saúde Mental e Trabalho (SM \& T) aponta para uma tendência a um amadurecimento conceitual dessa subárea do Campo da Saúde do Trabalhador (Sato \& Bernardo, 2005). Apesar desse crescimento, não existe consenso em termos de marco teórico utilizado nessas pesquisas. Pelo contrário, a SM \& T se coloca num campo interdisciplinar complexo e abrangente (SeligmannSilva, 1997). De modo heterogêneo, muitos autores (Borges, 2001; Lima, Araújo, Lima \& Neves, 1997; Sato, 1996; Seligmann-Silva, 1995) têm discutido a organização do trabalho e seus efeitos sobre a saúde dos trabalhadores. O controle, em especial, parece ser objeto de incessante conflito entre a organização do trabalho, que visa garantir que objetivos, metas e planos sejam atingidos, e os trabalhadores, visto que sua saúde dele depende (Lacaz \& Sato, 2006).

1 Este trabalho foi elaborado a partir da disciplina Trabalho, Subjetividade e Saúde, ministrada pela prof. Dra. Leny Sato, no curso de Pós-Graduação em Psicologia Social do Instituto de Psicologia da USP.

2 Doutora em Saúde Coletiva pela Universidade Federal de São Paulo. 
Sato (1996), por exemplo, entende que as consequências positivas ou negativas da organização do trabalho sobre a saúde dos trabalhadores dependem, exatamente, do controle do trabalhador sobre os contextos de trabalho. A autora aponta três dimensões do controle: a familiaridade com a tarefa (ligada à capacidade de identificação daquilo que incomoda), o poder, entendido como a possibilidade de interferir no planejamento do trabalho, e os limites subjetivos (ou seja, quanto e como o trabalhador aguenta as pressões de trabalho).

Em outro texto (Sato, 2002a, p. 41), ela cita variados estudos que "associam a ausência e a insuficiência de controle do trabalhador sobre o seu contexto de trabalho" às diversas afeç̧ões, que vão de problemas osteoarticulares aos distúrbios de saúde mental. De acordo com ela, "muitas são as evidências de que a insuficiência de controle é explicativa de problemas de saúde" (p. 41).

Em um estudo posterior, Sato (2002b), ao abordar as negociações cotidianas desenvolvidas pelos trabalhadores, descreve que estes criam formas de resistir à racionalidade imposta pela organização, visando melhorar sua sintonia com os contextos de trabalho, seja individual, seja coletivamente. Desse modo, as ações adaptativas teriam o fim de adequar o trabalho às características e limites subjetivos dos trabalhadores que a operam. Enfatiza, também, os ajustes que os trabalhadores fazem para executar a atividade real do trabalho, à medida que adquirem maior controle do trabalho (familiaridade e poder), ajustes estes que permitem o replanejamento do trabalho, ou seja, processos de negociação. Essa ação teria como objetivo amenizar os esforços de trabalho, manifestar a resistência política ao poder e controle impostos, assim como tornar possível a execução do trabalho, planejado por outro.

As concepções descritas auxiliam no entendimento dos processos organizativos e dos mecanismos de dominação e resistência pautados por eles. Esses diferentes pontos de vista têm em comum a compreensão da organização como lugar de conflitos e de relações de poder, nas quais o controle no espaço organizacional é objeto de disputa entre os diversos atores (Sato, 2002a). Isso porque é através do exercício do controle que se possibilita a regulação das atividades, a revisão dos objetivos, metas e meios para atingi-los, de modo a compatibilizar pressões do ambiente e necessidades (Sato, 2002b).

Nesse aspecto, o controle do trabalhador pode ser entendido como a capacidade de conhecer e interferir sobre o trabalho (Sato, 2002a). Assim, tomaremos como quadro referencial deste estudo a noção de controle como a possibilidade de os trabalhadores conhecerem o que os incomoda, os faz sofrer, adoecer, morrer e acidentar-se, articulada à viabilidade de interferir em tal realidade, como sujeitos (Lacaz, 2000; Lacaz \& Sato, 2006).

O objetivo do presente texto é investigar como esse conceito atravessa as conclusões de duas pesquisas consideradas como referências para a área de $\mathrm{SM} \& \mathrm{~T}$. Os estudos abordados serão: a) a experiência de Le Guillant com as telefonistas parisienses, que o levou a caracterizar uma neurose específica nessa classe, e b) as pesquisas no campo da Psicodinâmica do Trabalho, que tem em Dejours seu principal expoente.

Com a finalidade de fazer um breve levantamento teórico e revisar as concepções sobre o controle do trabalho, apresentaremos resumidamente as duas pesquisas em SM \& T, a fim de discutir a importância do controle sobre o processo saúde-doença dos trabalhadores. A partir dessas duas revisões bibliográficas, analisaremos o fio condutor deste ensaio: o conceito de controle sobre o trabalho, tentando estabelecer o que distancia e o que aproxima as opções teóricas de Le Guillant e Dejours. 


\section{A pesquisa em $\mathrm{SM} \& \mathrm{~T}$ : a mediação do controle do trabalho no processo saúde-doença}

Dentro do campo da Saúde Mental e Trabalho, alguns autores se destacam como referência de estudo, sendo Christophe Dejours uma unanimidade nos textos que revisam os campos de atuação da SM \& T (Jacques, 2003; Fernandes, Melo, Gusmão, Fernandes \& Guimarães, 2006; S. Fernandes, 1996; Seligmann-Silva, 1995). Por outro lado, Louis Le Guillant é um teórico cuja obra é relativamente desconhecida no Brasil, mas sua originalidade e relevância marcaram a construção do campo da SM \& T (Lima, 2006). Nosso interesse nesses dois autores se dá, em especial, pelo fato de eles terem estudado um mesmo público alvo operadoras de telefone, em Paris - e levantado, nesses estudos, a questão do controle como central no adoecimento/sofrimento mental dessas trabalhadoras.

Utilizamos como metodologia a pesquisa bibliográfica, na qual fizemos uma revisão teórica ampla dos textos ${ }^{3}$ em que esses autores fazem alusão às pesquisas com as telefonistas, buscando comparar suas visões sobre o papel do controle no adoecer. Nossa principal categoria de análise foi as diferenças nas vertentes teóricas desses autores.

Os textos sobre a neurose das telefonistas analisados foram:

-De Louis Le Guillant, "A neurose das telefonistas, Algumas observações metodológicas a propósito da neurose das telefonistas" e "O trabalho e a fadiga", todos publicados no livro Escritos de Le Guillant (Le Guillant, 2006);

-De Christophe Dejours, "A exploração do sofrimento", publicado no livro A Loucura do Trabalho (Dejours, 1987).

Outros textos dos autores ou a respeito deles foram consultados, para complementação de informações sobre as abordagens teóricas e outros dados complementares.

Louis Le Guillant foi um psiquiatra francês ligado à medicina social, apontado como um dos fundadores do movimento de Psiquiatria Social (Lima, 2006); ao lado de Paul Sivadon, foi precursor da Psicopatologia do Trabalho em seu país (Souza \& Athayde, 2006). Le Guillant buscava uma nova forma de ver as doenças mentais, em que o médico e o psicólogo não fossem meras "testemunhas" do adoecer, mas se envolvessem com a realidade do sujeito, buscando a "origem real" das doenças (Le Guillant, 2006). Com uma visão materialista do trabalho, sob influência teórica marxista (Souza \& Athayde, 2006), criticou a individualização e o "subjetivismo" de outros especialistas em saúde mental. Para Souza e Athayde (2006) o autor estava interessado nas contradições, incompatibilidades e conflitos que a condição patogênica contém e tenta impor aos sujeitos. Le Guillant acreditava que o sofrimento mental dos trabalhadores resultava das condições e da organização do trabalho.

O excessivo aumento das licenças de longa duração por causas psicológicas e o extremo nervosismo das telefonistas levaram Le Guillant e seus colaboradores (1984) a estudar a categoria. $\mathrm{O}$ autor repudiava o fato de que os médicos tentavam caracterizar a doença como resultante de predisposições pessoais ou, apenas, das condições de vida, e buscou demonstrar o vínculo entre tal quadro e as condições de trabalho. Para isso, utilizou uma metodologia que unia o estudo de grupos homogêneos de trabalhadores, com a escuta de casos particulares: "Deve-se começar por escutar uma telefonista [...], além de observá-los na vida cotidiana e na atividade profissional" (Le Guillant, 2006).

Ao se propor o estudo das Neuroses das Telefonistas, publicado inicialmente em 1956, Le Guillant et al. (1984) relacionaram a "Síndrome Geral da Fadiga Nervosa" a certas condições de trabalho, que pressupunham a diminuição dos gastos de energia muscular e uma aceleração correlativa de rapidez dos atos de trabalho, que causariam um aumento dos esforços

3 Publicados em português. 
de atenção, precisão e velocidade. Segundo Souza e Athayde (2006), a análise da fadiga, para os autores de Neurose das Telefonistas, considera três planos: o fisiológico, o psicoafetivo e o psicossocial, tendo como ponto de partida o trabalho e as relações objetivas criadas na interação do trabalhador com seu trabalho. Assim, a fim de investigar esse processo de desgaste à saúde mental das trabalhadoras, Le Guillant (apud Lima, 2002) se voltou para o conjunto dos sintomas apresentados pela pessoa, em seu meio e por sua história.

Dessa maneira, Le Guillant e Begoin (2006) recolheram dados clínicos indispensáveis, que foram sistematizados nas seguintes categorias de sofrimento mental: uma síndrome subjetiva comum; alterações do humor e do caráter; alterações do sono; um conjunto de manifestações somáticas variáveis e a repercussão dessas diferentes alterações sobre a vida das trabalhadoras. Conforme observado na pesquisa, as alterações se referiam a indisposições que, à primeira vista, pareciam pouco graves, mas tornavam a vida dessas trabalhadoras quase intolerável: "por lhes suprimir toda a possibilidade de calma e felicidade" (p. 9). Por outro lado, apontavam que a gravidade dessas alterações estava no fato de elas não desaparecerem nos períodos de descanso semanal. Pouco a pouco, os sintomas se tornavam permanentes, agravando-se e multiplicando.

Os autores buscavam delimitar os elementos do trabalho mais patogênicos percebidos pelas trabalhadoras, que apontaram o rendimento e o controle como os mais importantes. $\mathrm{O}$ cálculo do rendimento influenciava fortemente o ritmo de trabalho, visto que era determinado por uma média de produtividade a ser cumprida (que gerava competições, disputas e conflitos entre as próprias telefonistas). O controle da organização sobre o trabalho se dava através das "mesas de escuta" ${ }^{4}$ e por controladoras, que circulavam nos espaços de trabalho, a fim de adequar os modos operatórios às prescrições. Além disso, as idas ao banheiro eram limitadas à duração de cinco minutos e deveriam ser anunciadas às controladoras, para autorização. A monotonia causada pela automação crescente e a execução de um trabalho mecânico ${ }^{5}$ também foram mencionadas, pelas telefonistas, como condições de trabalho relacionadas aos sintomas.

Nesse estudo, o autor percebeu que a relação entre trabalho e sofrimento mental estava especialmente ligado a uma forma de controle da organização sobre o trabalhador: a imposição do ritmo do trabalho, em tarefas repetitivas, que exigiam "um elevado grau de rapidez, atenção e precisão" (Le Guillant \& Begoin, 2006) e atingiam o sistema nervoso mais do que o sistema muscular.

Ao analisar a necessidade de rapidez nas operações das telefonistas, os autores afirmam que era fundamental que elas estivessem nervosas para que o trabalho ocorresse na velocidade prescrita, ou seja: "(...) as doenças por elas enfrentadas seriam necessárias para o bom andamento do trabalho" (Souza \& Athayde, 2006, p. 14). É importante notar, no entanto, que são as próprias condições de trabalho que levam a esse adoecer necessário para a aceleração. As estratégias de controle teriam, como função, promover tal adoecimento.

Frisamos que as dimensões do controle até aqui apontadas dizem respeito tanto ao controle excessivo da organização sobre o trabalho quanto à ausência ou controle reduzido das próprias trabalhadoras sobre o trabalho que elas desenvolvem. No nosso entender, a monotonia e a mecanização do trabalho também poderiam ser analisadas como dimensões do controle, visto que o entendemos como a capacidade de conhecer e interferir sobre o trabalho (Sato, 2002a). Além disso, foi observado que, nos postos em que a vigilância e a exigência do rendimento eram menos rigorosas, nos quais as telefonistas tinham maior iniciativa, estas apresentavam menos alterações. Os autores dão fortes indícios de que o controle das telefonistas (e dos trabalhadores) sobre o próprio trabalho é um fator importante na

4 Postos de trabalho nos quais se monitoravam as conversas telefônicas das trabalhadoras, com objetivo de controlar a adequação aos procedimentos.

5 De acordo com os depoimentos das trabalhadoras, o trabalho mecânico estaria ligado a não poder organizar, elas mesmas, o trabalho, pelo o fato de não poderem acrescentar nada ao trabalho e de trabalharem como robôs. 
determinação do processo de adoecimento. No entanto, se Le Guillant afirma que "a maior parte das telefonistas queixa-se, antes de tudo, do controle", ele julga que o controle é "simplesmente uma condição de rendimento" (Le Guillant, 2006, p. 235). Para esse autor, a realidade concreta do trabalho, como o ritmo acelerado, a exigência de precisão e de atenção, e as consequências dessa realidade para o sistema nervoso eram as causas da neurose das telefonistas.

Vale ressaltar que, no texto Introdução à psicopatologia social (Lima, 2006), Le Guillant aponta a ocorrência de variações das manifestações psicopatológicas sob influência de grandes acontecimentos sociais, assim como observa um número diferente de distúrbios psíquicos em estruturas sociais diferentes. Desse modo, para o autor, as condições de vida impostas aos pacientes são determinantes das doenças mentais e, consequentemente, da sua saúde. Nessa perspectiva, é possível afirmar que sua concepção de saúde está imbricada nas relações sociais, acreditando na determinação social do adoecimento. Podemos entender, portanto, que, para Le Guillant, um ambiente com condições "saudáveis" - sem as exigências impostas pelo controle da organização sobre o trabalho - garantiria um trabalho que não adoece, independente do ser humano que o realiza.

Christophe Dejours é médico do trabalho, psiquiatra e psicanalista e principal representante da teoria da Psicodinâmica do Trabalho. Em suas pesquisas, Dejours e colaboradores observaram que os trabalhadores não se mostravam passivos em face das exigências e pressões organizacionais. Muito pelo contrário, apresentavam-se como capazes de se proteger dos efeitos nefastos à Saúde Mental, construindo sistemas defensivos coletivos (Athayde, 2005). O fato de a organização do trabalho não afetar igualmente a saúde de todos os trabalhadores, submetidos a ela, significaria que o privado - a estrutura psíquica - vai prevalecer sobre o social - o trabalho (Dejours \& Abdoucheli, 1994, p. 123). Desse modo, os autores se deslocam do foco das doenças mentais para o sofrimento e defesas, buscando compreender o enigma da normalidade, diante da violência da organização do Trabalho. Ao mesmo tempo em que estabelecem uma passagem da abordagem da Psicopatologia do Trabalho para a Psicodinâmica do Trabalho, valorizando, então, as dimensões intrapsíquicas e intersubjetivas presentes no sofrimento e nas estratégias de sua evitação no local de trabalho.

A hipótese desse autor é a de que a organização do trabalho não leva de modo direto a doenças mentais específicas, mas pode bloquear a descarga da energia psíquica que permite às pessoas equilibrar sua tensão psíquica interior. Essa organização, pensada como submissão ao desejo do outro, pode diminuir a liberdade que cada um necessita para utilizar as formas de descarga de sua preferência, ou seja, pode se opor à livre atividade do aparelho psíquico (Dejours, 1987, 1994), restringindo a variabilidade.

Dejours, assim como Le Guillant, analisa o sofrimento no trabalho das telefonistas da $\mathrm{PTT}^{6}$, utilizando, para isso, pesquisa realizada por Dominique Dessors. Tal pesquisa, na análise de Dejours, demonstra o "verdadeiro terror" sentido pelas telefonistas a partir da escuta de controladoras que podem ouvi-las, sem que elas o saibam, e que dão notas ao seu atendimento. As trabalhadoras colocam que dependem do "bom humor" da controladora para uma boa nota, pois "se a chefe do controle estiver de 'mau-humor', haverá sempre qualquer coisa para comentar" (Dejours, 1987, p. 98). Para o autor,

O eixo central dessa violência do poder baseia-se no estado permanente de poder ser controlado. Não se pode imaginar uma disciplina mais eficaz ou perfeita que a existente, pelo fato de se poder ser controlado a qualquer momento, sem mesmo saber em que momento esse controle é exercido. De certo modo, é a construção artificial de um autocontrole. Pois ter medo de ser vigiado é vigiar-se a si mesmo (Dejours, 1987, p. 102).

6 Postes, Télégrames et Télecommunication, empresa estatal francesa responsável pelos correios, telégrafos e telefonia, mesma empresa estudada, anos antes, por Le Guillant e que o levou a escrever sobre a neurose das telefonistas. 
A falta de controle sobre o trabalho, que as telefonistas sofrem, mostra-se na estruturação extrema do discurso a que estão submetidas, reduzindo-o a uma série de frases predeterminadas que, por vezes, as fazem se sentir estúpidas.

Dejours também percebe que as exigências de tempo e ritmo no atendimento são intensas e contaminam a vida pessoal das telefonistas, levando-as a comportamentos estereotipados, aceleração e ansiedade (Dejours, 1987, p. 100). No entanto, para ele, ao invés de o excesso do controle e o ritmo intenso levarem a uma neurose, essas formas de organização do trabalho se utilizam da estrutura psíquica já existente nas telefonistas para aumentar a carga de trabalho. $\mathrm{O}$ excesso de controle é usado como uma estratégia para enervar as telefonistas, assim como o conteúdo inadequado que as faz se sentirem tolas, fazendo surgir uma agressividade que é explorada para aumentar a produtividade.

Sem liberdade para usar uma válvula de escape pessoal, que teria como função lidar com o aumento da carga psíquica causada por essa agressividade, "a única solução autorizada é reduzir o tempo da comunicação e empurrar o interlocutor para desligar mais depressa" (Dejours, 1987, p. 103).

Nesse sentido, o sofrimento não é causado pelo trabalho em si, mas utilizado pela organização para produzir mais trabalho, sendo o controle o instrumento usado para o aumento da performance.

Dejours conclui que "o que é explorado pela organização do trabalho não é o sofrimento em si, mas principalmente os mecanismos de defesa utilizados contra esse sofrimento" (Dejours, 1987, p. 104), que provém de um trabalho estereotipado e que não permite a expressão dos desejos do indivíduo, pois proíbe a variabilidade e aumenta a carga psíquica que será utilizada para intensificar o ritmo do trabalho.

Sobre outro foco, Dejours (1986), ao rever o conceito de saúde utilizando como referência as noções trazidas pela fisiologia, psicossomática e psicanálise, resgata a noção de variabilidade, na qual o que predomina no funcionamento humano, físico, psíquico e social é a mudança, e não a estabilidade. De certa maneira, a noção de variabilidade se relaciona com a possibilidade de as pessoas terem controle sobre seu próprio corpo ${ }^{7}$, sobre a organização de seu trabalho e sobre sua própria vida. Partindo desse conceito, promover saúde é assumir e respeitar essa variabilidade:

A saúde é a liberdade de dar a esse corpo a possibilidade de repousar, é a liberdade de lhe dar o que comer quando tem fome, de fazê-lo dormir quando ele tem sono (...). É, portanto, a liberdade de adaptação. (...) Bem-estar psíquico, em nosso entender, é, simplesmente, a liberdade que é deixada ao desejo de cada um na organização de sua vida (p. 11).

\section{As diferenças de abordagem}

Os dois teóricos apresentados têm seu olhar voltado para o mesmo fenômeno - o controle sobre o trabalho - e em uma mesma população - as trabalhadoras de telefonia, em Paris. No entanto, devido às suas teorias de base, tal fenômeno será analisado de forma quase oposta por ambos.

Le Guillant, de tendência materialista, baseava-se, em especial, na obra de Karl Marx e George Politzer (como aponta Lima, 2006, p. 11). Buscava ver os fenômenos de adoecimento

7 No caso das telefonistas estudadas por Le Guillant (1984), esta possibilidade de controle sobre o corpo é interditada com os limites sobre o tempo e frequência de idas ao banheiro, impostas pela organização. 
mental ligado às condições de trabalho de forma mais concreta e ligá-los, principalmente, à organização do trabalho e aos modos de dominação. Assim sendo, não é difícil supor que o tema da disputa do controle do trabalho lhe chamasse a atenção.

Por outro lado, Dejours é psicanalista e foca seu olhar sobre os fenômenos subjetivos do trabalho. Se, em A loucura do trabalho (1987), a influência da psicanálise já pode ser bastante sentida, é em A psicodinâmica do trabalho (1994) que tal teoria o levará a se voltar para o interior do sujeito e sua vida intrapsíquica. Assim, considera os fenômenos ligados ao sofrimento no trabalho como resultantes da exploração dos mecanismos de defesa, criados para a manutenção dos conteúdos inconscientes, pela organização do trabalho.

A escolha teórica de cada um desses autores terá consequências definitivas em suas conclusões na análise do sofrimento das telefonistas. Para Le Guillant, as causas do adoecimento, que levariam a uma neurose típica - a neurose das telefonistas -, estão na situação concreta do trabalho: o ritmo acelerado, caracterizado por tarefas repetitivas, que exigem rapidez, atenção e precisão, tem impacto sobre o sistema nervoso. Este era, portanto, uma forma de "psicopatologia social", cuja etiologia estaria ligada à divisão de classes e à sujeição do trabalhador ao ritmo imposto pelo capitalista. Mesmo que esse sofrimento psíquico seja utilizado pela organização do trabalho para aumentar o rendimento, como Le Guillant aponta no texto Neurose das Telefonistas (Le Guillant et al., p. 179), ele é resultante não de uma interioridade psíquica, mas do contato com a realidade concreta das condições de trabalho.

A visão de Dejours é radicalmente diferente. Para ele, o subjetivo e o privado estão na raiz da questão do sofrimento mental, sendo a organização do trabalho responsável pela exploração dos mecanismos de defesa criados para lidar com os processos inconscientes. Nesse sentido, o sofrimento está relacionado à formação da personalidade, de acordo com parâmetros psicanalíticos, e tanto o social quanto o concreto do trabalho passam a pano de fundo no adoecer.

É clara a oposição entre as condições de trabalho, que têm como alvo o corpo do trabalhador, como assume Le Guillant, e a divisão do trabalho, que atua no nível do funcionamento psíquico, como coloca Dejours.

As diferenças desses autores terão impacto na centralidade e significado do trabalho no processo saúde-doença. A visão materialista de Le Guillant o leva a colocar o trabalho como fator central na determinação da neurose das telefonistas:

(...) por um lado, em uma organização do trabalho dominada pela busca do máximo rendimento - do lucro máximo -, displicente e não tanto ignorante em relação aos problemas humanos e, por outro, para além das condições materiais e morais, nas estruturas sociais que as comandam (Le Guillant, 2006, p. 229).

Com o deslocamento dos estudos para a Psicodinâmica do Trabalho, Dejours e seus colaboradores tendem a retirar a centralidade e significado do trabalho na saúde, visto que o objeto passa a ser o sujeito e não o trabalho em si, agora entendido como mediador entre inconsciente e ordem coletiva (Athayde, 2005).

Vê-se o impacto dessas concepções nos dispositivos de atuação propostos e utilizados pelos dois autores. Le Guillant se utiliza principalmente de pesquisas de cunho epidemiológico, com observações dos postos de trabalho e entrevistas voltadas à descrição das condições que levaram ao adoecimento, como é possível inferir de suas pesquisas com as telefonistas. Já Dejours defenderá a utilização da pesquisa-ação cuja solicitação precisa, necessariamente, partir do coletivo dos trabalhadores, e o próprio conteúdo dessa solicitação será objeto de análise (como proposto no anexo sobre metodologia em psicopatologia do trabalho, em Dejours, 1987). 


\section{Algumas conclusões}

O presente artigo não tem a pretensão de trazer proposições definitivas sobre os dois autores, posto que só parte de sua obra foi utilizada - tendo como foco suas observações a respeito das telefonistas. Analisando tais textos, alguns pontos parecem claros:

-Que o controle sobre o trabalho está, de alguma forma, envolvido com o adoecimento e/ou o sofrimento no trabalho. Direta ou indiretamente, os dois autores parecem concordar que, à medida que as organizações aumentam seu controle sobre os processos de trabalho e sobre o corpo dos trabalhadores, aumentam também os números de transtornos mentais ligados ao trabalho. Diferirá, no entanto, a forma de se compreender esse adoecimento, nos dois autores. Enquanto para Le Guillant tal sofrimento estaria ligado às condições concretas do trabalho, para Dejours ele estaria ligado à diminuição da possibilidade de variabilidade necessária para a atuação dos mecanismos de defesa individuais;

-Que as relações do controle do trabalho estabelecidas nas organizações, mesmo que expressem poderes multiformes entre trabalhadores e organizações, são assimétricas, visto que a organização, em nome da produtividade, intensifica o controle sobre o trabalhador, seja à medida que utiliza o sofrimento individual e particular, ligado ao sujeito e sua interioridade, para se produzir mais (Dejours, 1987), seja no entendimento de Le Guillant, de que as doenças são produzidas e mantidas pelo trabalho para que este ocorra na velocidade necessária (Souza e Athayde, 2006), ou mesmo quando estabelece a relação entre produção e cálculos de rendimentos, promovendo a aceleração correlativa de rapidez dos atos de trabalho pelas trabalhadoras (Le Guillant, 1987);

-Que a centralidade do conceito de controle sobre o trabalho aparece nos dois autores, mas de forma distinta. Para Le Guillant, a forma de esse controle atuar, no caso das telefonistas, está ligado às condições concretas de trabalho sobre elas, através da aceleração do ritmo, do excesso de padronização dos comportamentos e de uma vigilância severa. Por outro lado, o controle será categoria essencial na abordagem de Dejours, pois o seu conceito de saúde exige que as pessoas se adaptem aos processos laborais, para garantir a utilização das descargas psíquicas preferidas que possam aliviar suas tensões inconscientes;

-Que o controle dos trabalhadores sobre seus comportamentos e os processos de trabalho seria positivo à saúde dos trabalhadores, visto que respeita a variabilidade, dando possibilidade ao trabalhador de escolher ou modificar seu modo operatório (Dejours, 1986), e altera a realidade concreta do trabalho, como o ritmo, as exigências e as consequências à saúde (Le Guillant, 2006).

No entanto, mesmo concordando que as relações entre o sujeito e o trabalho possam trazer efeitos prejudiciais à sua saúde, como acabamos de ver, é necessário refletir sobre o posicionamento desses dois autores e qual o impacto dessa posição para o entendimento e as práticas em Saúde Mental e Trabalho. Ambos vão além da simples causalidade que caracterizou a medicina higiênica e epidemiológica do século XIX ${ }^{8}$, mas, por vezes, parecem esbarrar na discussão que contrapõe o homem e o meio em que vive. Ao caracterizar a psicopatologia do trabalho como resultante da exploração das defesas psíquicas inconscientes, Dejours corre o risco de minimizar a influência dos fatores concretos e negar a possibilidade de o trabalho estar intimamente ligado a um adoecer cujas origens são nas condições de trabalho. Tal maneira de ver as relações entre saúde mental e trabalho pode levar à compreensão de que o trabalho não é uma categoria central na discussão da SM \& T.

O impacto dessa concepção pode ser visto na ideia de adaptação do sujeito ao trabalho como uma possibilidade de "saúde". Ora, será que o sujeito pode se adaptar ao trabalho, 
independente das condições concretas nas quais ele ocorre? Bastaria, para isso, que o trabalho permitisse àquele trabalhador uma descarga adequada de sua energia psíquica?

Le Guillant, por outro lado, corre o risco contrário: ao colocar a ênfase do adoecer no impacto do concreto sobre o sujeito, pode nos levar à ideia de vitimização passiva do ser humano diante das condições impostas. Além disso, a atuação nas condições concretas não seria suficiente para, por exemplo, resolver a questão do empobrecimento do conteúdo do trabalho. Condições ideais de trabalho seriam suficientes para não levar ao sofrimento mental aquele indivíduo que não vê sentido no que faz?

O fenômeno aparenta ser mais complexo do que essas duas posições. A interioridade nos parece atravessada pelo concreto, de diversas formas, e, ainda assim, é impossível reduzi-la a um simples reflexo do que acontece no exterior. Um exemplo desse entrecruzamento deve ter ficado explícito, na década passada, em relação ao fenômeno das Lesões por Esforço Repetitivo (LER). Lima (1998), por exemplo, afirma que a discussão sobre o nome mais adequado para essa doença fez ver que "os fatores que contribuem para seu aparecimento dizem respeito tanto às condições quanto à organização do trabalho" (p. 202), tendo seu impacto tanto no corpo quanto no psiquismo. A autora concluirá: "apenas a análise de todo um conjunto de fatores e de suas inter-relações, além da abordagem da situação concreta de trabalho e das características pessoais do trabalhador é que nos permitirá compreender essa forma de adoecimento" (p. 216, grifos nossos).

Também Sato $(1996,2002$ a, 2002b) revê a atuação em SM \& T ao considerar as ações adaptativas e micronegociações cotidianas como formas de prevenção ao agravo à saúde do trabalhador. Tais estratégias não focam apenas as melhorias das condições concretas, mas também a ressignificação do trabalho.

Assim, antes de serem excludentes, as teorias de Le Guillant e Dejours parecem ser complementares, se admitirmos o fato de que a centralidade no trabalho é essencial para os estudos de Saúde Mental, entendendo, como Yves Clot (citado por Athayde, 2005, p. 989), que "são as relações entre atividade e subjetividade que devem estar no centro da análise. $\mathrm{O}$ trabalho é visto [...] não apenas como trabalho psíquico, mas como atividade concreta e irredutível, continente oculto da subjetividade no trabalho". O controle do trabalho e aquele sobre o trabalho também precisam assumir essa dimensão de centralidade, posto sua possibilidade, como assume Sato, de atuar sobre as condições de trabalho que afetam os sujeitos, assim como sobre a organização do trabalho e seu significado para os trabalhadores.

Finalmente, consideramos que as relações entre Trabalho e Saúde Mental devem ser analisadas em sua complexidade, abarcando as diferentes interfaces das condições, da organização, da possibilidade ou não de controle sobre o trabalho, assim como a dimensão da subjetividade dos trabalhadores. Nesse sentido, Dejours e Le Guilant nos oferecem importantes contribuições para a apreensão das situações reais de trabalho e da subjetividade aí envolvida, restando-nos a árdua tarefa de refletir sobre as intervenções necessárias para a promoção da saúde dos trabalhadores. 


\section{Referências}

Athayde, M. (2005). Resenha do livro Christophe Dejours: Da psicopatologia à psicodinâmica do trabalho. Cadernos de Saúde Pública, 21 (3), 984-990.

Borges, L. H. (2001). Sociabilidade, sofrimento psíquico e lesões por esforços repetitivos entre caixas bancários. São Paulo: Fundacentro.

Dejours, C. (1986). Por um novo conceito de saúde. Revista Brasileira de Saúde Ocupacional, 54 (4), 7-11.

Dejours, C. (1987). A loucura do trabalho. São Paulo: Oboré.

Dejours, C. (1992). Uma nova visão do sofrimento humano nas organizações. In J. F. Chanlat (Org.), O indivíduo na organização: dimensões esquecidas (pp. 149-175). São Paulo: Atlas.

Dejours, C. (1994). A carga psíquica do trabalho. In C. Dejours \& E. Abdoucheli (Orgs.), Psicodinâmica do trabalho. São Paulo: Atlas.

Dejours, C. \& Abdoucheli, E. (1994). Psicodinâmica do trabalho. São Paulo: Atlas.

Dejours, C., Dessors, D. \& Desriaux, F. (1993). Por um trabalho fator de equilíbrio. Revista de Administração de Empresa, 33 (3), 98-104.

Fernandes, J. D., Melo, C. M. M., Gusmão, M. C. C. M., Fernandes, J. \& Guimarães, A. (2006). Saúde mental e trabalho: significados e limites de modelos teóricos. Revista Latino-Americana de Enfermagem, 14 (5), 803 811.

Fernandes, S. R. P. (1996). Saúde e trabalho: controvérsias teóricas. Caderno CRH, 24 (25), 155-169.

Jacques, M. G. C. (2003). Abordagens teórico-metodológicas em saúde/doença mental \& trabalho. Psicologia e Sociedade, 15 (1), 97-116.

Lacaz, F. A. C. (2000). Qualidade de vida no trabalho e saúde/doença. Ciência e Saúde Coletiva, 5 (1), 151-161.

Lacaz, F. A. C. (2007). Conhecimentos, práticas em Trabalho-Saúde e as abordagens da medicina social e da medicina do trabalho no Brasil: final do século XIX até os anos 1950-60. Cadernos de Psicologia Social do Trabalho, 10 (1), 93-103.

Lacaz, F. A. C. \& Sato, L. (2006). Humanização e qualidade do processo de Trabalho em Saúde. In S. Deslandes (Org.), Humanização dos cuidados em saúde: conceitos, dilemas e práticas. Rio de Janeiro: Fiocruz.

Le Guillant, L. (2006). O trabalho e a fadiga. In M. E. A. Lima (Org.), Escritos de Louis Le Guillant: da ergoterapia à psicopatologia do trabalho (pp. 218-241). Petrópolis: Vozes.

Le Guillant, L \& Begoin, J. (2006). Algumas observações metodológicas a propósito da neurose das telefonistas. In M. E. A. Lima (Org.), Escritos de Louis Le Guillant: da ergoterapia à psicopatologia do trabalho (pp. 189-217). Petrópolis: Vozes.

Le Guillant, L., Roelens, R., Bégoin, J., Béquart, P., Hamsen, M. \& Lebreton, F. (1984). A neurose das telefonistas. Revista Brasileira de Saúde ocupacional, 17 (47), 7-11.

Lima, M. E. A., Araújo, J. N. G. \& Lima, F. P. A. (1998). L.E.R.: dimensões ergonômicas e psicossociais. Belo Horizonte: Health.

Lima, M. E. A. (1998). A dimensão psicológica. In M. E. A. Lima, J. N.G. Araújo \& F. P. A. Lima (Orgs.), L.E.R.: dimensões ergonômicas e psicossociais. Belo Horizonte: Health.

Lima, M. E. A. (2002). Esboço de uma crítica à especulação no campo da saúde mental e trabalho. In M. G. Jacques \& W. Codo (Orgs.), Saúde mental e trabalho: leituras. Petrópolis: Vozes.

Lima, M. E. A. (Org.). (2006). Escritos de Louis Le Guillant: da ergoterapia à psicopatologia do trabalho. Petrópolis: Vozes.

Sato, L. (1996). Trabalho e Saúde Mental. In Central Única dos Trabalhadores (Org.), Saúde, meio ambiente e condições de trabalho: conteúdos básicos para uma ação sindical. São Paulo: CUT.

Sato, L. (2002a). Saúde e controle no trabalho: feições de um antigo problema. In M. G. Jacques \& W. Codo (Orgs.), Saúde mental e trabalho: leituras. Petrópolis: Vozes. 
Sato, L. (2002b). Prevenção de agravos à saúde do trabalhador: replanejando o trabalho através das negociações cotidianas. Cadernos de Saúde Pública, 18 (5), 1147-1157

Sato, L. (2007). Processos cotidianos de organização do trabalho na feira livre. Psicologia Ë Sociedade, 19 (1), 95-102.

Sato, L. \& Bernardo, M. H. (2005). Saúde mental e Trabalho: os problemas que persistem. Ciência e Saúde Coletiva, $10(4), 869-878$.

Seligmann-Silva, E. (1995). Psicopatologia e psicodinâmica do trabalho. In R. Mendes (Org.), Patologia do trabalho. São Paulo: Atheneu.

Souza, P. C. Z. \& Athayde, M. (2006). A contribuição da abordagem clínica de Lous Le Guillant para o desenvolvimento da Psicologia do Trabalho. Estudos e Pesquisas em Psicologia, 6 (1), 6-19.

\section{Endereço para correspondência}

analuar@gmail.com, augusto@psicossocial.com.br

Recebido em: 01/10/2009

Revisado em: 11/04/2010

Aprovado em: 13/04/2010 